\title{
Does aspirin acetylate multiple cellular proteins? (Review)
}

\author{
LLOYD F. ALFONSO, KALKUNTE S. SRIVENUGOPAL and G. JAYARAMA BHAT \\ Department of Pharmaceutical Sciences and Cancer Biology Center, Texas Tech University \\ Health Sciences Center, 1300 Coulter Drive, Amarillo, TX 79106, USA
}

Received February 12, 2009; Accepted April 6, 2009

DOI: 10.3892/mmr_00000132

\begin{abstract}
Aspirin is a salicylate drug that is extensively used for its anti-inflammatory, antipyretic, analgesic and antithrombotic effects. More recently, it has been shown to decrease the incidence of cancers of epithelial origin. In most cases, aspirin is relatively safe. However, it does cause a host of adverse effects and toxicities, including gastrointestinal bleeding, ulcerations, nephrotoxicity and hypersensitivity reactions. Although the inhibition of cyclooxygenases by aspirin, which leads to its anti-inflammatory/analgesic properties, has been well studied, the mechanisms involved in its chemopreventive effects as well as some of its adverse effects are as yet ill-defined. Studies over the past decades suggest that, besides cyclooxygenases, aspirin acetylates other cellular proteins. These studies used radiolabeled ${ }^{3} \mathrm{H}$ or ${ }^{14} \mathrm{C}$ aspirin, the only approach used to date for the detection of proteins acetylated by aspirin. In a recent study using protein-specific anti-acetyl lysine antibodies and immunological methods, we demonstrated the ability of aspirin to acetylate the tumor suppressor protein p53. In this review, we present current research from the literature on the aspirin-induced acetylation of proteins. We also describe an immunological approach to detecting acetylated proteins in aspirin-treated cells, and demonstrate that multiple proteins are acetylated. Since post-translational modification of proteins, such as acetylation, may lead to the alteration of their function, it is possible that some of the hitherto unexplained beneficial or adverse effects of aspirin could occur as a result of these modifications. The identification of these novel acetylation targets of aspirin represents a new area for investigation.
\end{abstract}

\section{Contents}

1. Introduction

2. Acetylation of cyclooxygenases by aspirin

3. Acetylation of human serum albumin by aspirin

Correspondence to: Dr G. Jayarama Bhat, Department of Pharmaceutical Sciences, Texas Tech University Health Sciences Center, 1300 Coulter Drive, Amarillo, TX 79106, USA

E-mail: jayarama.gunaje@ttuhsc.edu

Key words: aspirin, acetylation, cyclooxygenases, albumin, platelets, fibrinogen, hemoglobin, p53
4. Acetylation of fibrinogen and platelet proteins by aspirin 5. Acetylation of other proteins and biomolecules by aspirin

6. Acetylation of p53 by aspirin

7. Aspirin acetylates multiple cellular proteins

8. Summary

\section{Introduction}

Aspirin (acetylsalicylic acid or ASA) is currently one of the most frequently used drugs in the world. It is well known that use of aspirin prevents pain, inflammation and fever (1). Aspirin is also widely used for its anti-thrombotic and cardioprotective properties, while more recent studies have indicated its potential use in chemoprevention $(2,3)$. Aspirin consists of acetyl and salicylate moieties, both of which have their own individual targets. While the salicylate group has been implicated in the anti-inflammatory properties of aspirin via the inhibition of NF- $\kappa \mathrm{B}$ (4-6), the acetyl group causes the inactivation of cyclooxygenases (COXs) through the acetylation of serine residues (1,7). However, it has been demonstrated that aspirin is also able to acetylate distinct cellular components, including proteins, hormones and nucleic acids (8).

Aspirin is generally absorbed intact in the gastrointestinal tract (9-11). As the drug circulates in the plasma, it is hydrolyzed to the acetate ion and salicylic acid (11). Hydrolysis is enhanced during passage through the liver and other organs. Using radiolabeled ${ }^{3} \mathrm{H}$ or ${ }^{14} \mathrm{C}$ aspirin, it was shown that aspirin acetylates proteins in vitro and in vivo through a transacetylation reaction $(8,12-15)$. However, detailed study on its ability to acetylate cellular proteins has not been carried out, as there is a lack of sensitive techniques. One major problem with the use of radiolabeled ${ }^{3} \mathrm{H}$ or ${ }^{14} \mathrm{C}$ aspirin in determining the acetylation of proteins is that the absolute amount of radioactivity transferred to the protein is relatively small and difficult to quantify due to the low specific activity of the radioactive aspirin (16). In this review, we provide an up-to-date account of the literature on the effects of aspirin on the acetylation of cellular proteins, and discuss an immunological approach for the detection of acetylated proteins in aspirin-treated cells.

\section{Acetylation of cyclooxygenases by aspirin}

Cyclooxygenases (COXs) catalyze the rate-limiting step in the synthesis of prostaglandins. All COX enzymes are homodimers and membrane-bound heme-containing glycoproteins 
primarily located in the endoplasmic reticulum (1). COX has both peroxidase and cyclooxygenase activities. Aspirin has been shown to selectively acetylate the hydroxyl group of a serine residue at position 530, located 70 amino acids from the C-terminus of the COX-1 enzyme (1,7). Acetylation of COX-1 results in irreversible inhibition of its activity, thus a new enzyme must be synthesized for more prostanoids to be produced. Acetylation of COX-1 at serine 530 inhibits its cyclooxygenase but not its peroxidase activity. The stoichiometry of this reaction is $1: 1$, with one acetyl group transferred per enzyme monomer of this dimeric protein $(1,17)$. COX-1 and -2 contain an overall homology of $60 \%$ between their amino acid structures, and aspirin binds to serine 516 in the active site of COX-2 in the same way as it binds to serine 530 in the active site of COX-1. Due to the presence of a slightly larger active site in COX-2, the degree of inhibition is reported to be much lower than in COX-1 (17). Inactivation of these enzymes leads to decreased synthesis of prostaglandins, which are responsible for pain and fever.

\section{Acetylation of human serum albumin by aspirin}

Human serum albumin (HSA) is the most abundant plasma protein, comprising approximately half of the blood serum protein. It is a soluble protein that is produced by the liver and is mainly involved in the transport of biomolecules, such as hormones, fatty acids and various drugs. Pinckard et al demonstrated that aspirin acetylates HSA under physiological conditions in vitro (8). This was also confirmed to occur in vivo by a separate study (13). The acetylation of HSA by aspirin in vivo and in vitro enhanced its capacity to bind a marker anion, acetrizoate (18), suggesting that this protein modification alters its conformation. The modification has been reported to result in the formation of $\mathrm{N}$-acetyl derivatives, with the $\varepsilon$-amino group of lysine being considered a probable site of this action $(8,16,18)$. It was shown that sera from rheumatic patients who had received extensive aspirin therapy contained anti-acetylated serum albumin antibodies $(14,19,20)$, suggesting that aspirininduced acetylation of proteins could trigger immune responses. Aspirin also appears to inhibit the glycation of albumin through rapid acetylation in vivo and in vitro (21), indicating that it can interfere with protein functions, including ligand binding properties (18).

\section{Acetylation of fibrinogen and platelet proteins by aspirin}

Fibrinogen is a soluble plasma glycoprotein produced by the liver that is converted to fibrin by the serine protease thrombin during the coagulation cascade. In addition to its anti-platelet effect, occurring as a result of the inhibition of cyclooxygenases, aspirin has been shown to have hypoprothrombinemic and fibrinolytic effects (22). It was revealed that aspirin acetylates fibrinogen in vitro (8) and in vivo (22) to form $\varepsilon$ - $\mathrm{N}$-acetyl-lysine derivatives. An average of three acetyl substitutions were observed to occur on each fibrinogen molecule, and the $\mathrm{N}$-acetylation of the lysine residues of fibrinogen by aspirin appeared to be involved in the increased susceptibility of fibrin clots to lysis (22). Aspirin at micromolar concentrations has also been shown to acetylate an $85-\mathrm{kDa}$ protein in platelets localized to the particulate fraction. This reaction was correlated with the inhibition of platelet function (16).

\section{Acetylation of other proteins and biomolecules by aspirin}

Aspirin has also been shown to acetylate proteins and biomolecules such as hemoglobin, DNA, RNA and histones, as well as several plasma constituents, including hormones and enzymes (8). Best characterized of these is the hemoglobin molecule ( $\mathrm{HbA}$ and $\mathrm{HbS}$ ), which was demonstrated to be modified in in vivo and in vitro reactions $(10,23,24)$. Both $\alpha$ and $\beta$ chains were shown to be acetylated by aspirin, and the identified sites included ßLys-59, ßLys-144 and BLys-90 (25); however, another study showed the primary target to be BLys-82 (26). Although there were claims that this modification increases the oxygen affinity of $\mathrm{HbS}$ (24), other reports could not substantiate this finding $(27,28)$. As observed with HSA, the glycation of hemoglobin was inhibited by aspirin, though the required dose was considerably higher (21).

There is also evidence for the modification of erythrocyte and platelet membrane proteins by aspirin, which induces local conformational changes in these membranes (29). Another study revealed that aspirin at micromolar concentrations acetylated RBC membrane peptides (30). Elsewhere, aspirin was shown to acetylate renal cortical and medullary proteins after in vivo administration (15). This acetylation of proteins was rapid and increased the half-life of these proteins to more than $130 \mathrm{~h}$. There is also a study that demonstrated the ability of aspirin to acetylate ubiquitin in vitro (31).

Aspirin is reported to have a protective effect against the development of cataracts. Implicated in this anti-cataract effect is the acetylation of lens $\gamma$-crystallins, shown to be caused by aspirin $(32,33)$. Both the lysyl and cysteinyl residues of bovine $\gamma$-crystallins were demonstrated to be acetylated by aspirin (33). Non-enzymatic glycosylation of proteins is a secondary complication in diabetes mellitus. Therefore, it was postulated that acetylation of these proteins by aspirin could reduce the progress of secondary biochemical lesions $(21,34)$. In other studies, in vivo administration of radiolabeled ${ }^{3} \mathrm{H}$ or ${ }^{14} \mathrm{C}$ aspirin showed that the acetyl group of aspirin bound to several proteins, glycoproteins and lipids of the glandular and non-glandular regions of the stomach, kidney, liver and, to a lesser degree, bone marrow (12). This clearly demonstrated the ability of the actetyl group to reach distant organs where sideeffects are manifested. Therefore, it is argued that the high degree of acetylation of these biomolecules may be related to the development of some of the adverse effects of aspirin.

\section{Acetylation of p53 by aspirin}

In a recent study, we demonstrated that aspirin at the physiologically achievable concentration of $100 \mu \mathrm{M}$ acetylates the tumor suppressor protein p53 (35). p53 is a key regulator of apoptosis, and is acetylated at several defined sites by cellular acetyltransferases in response to various stresses, including DNA damage. The ability of aspirin to acetylate p53 was demonstrated in immunoblotting experiments using commercially available anti-acetyl p53 antibodies specific for the recognition of acetylated lysine at position 382 (K382). Increased acetylation of p53 by aspirin was correlated with increased p53 DNA binding activity and the expression of two of its target genes, $\mathrm{p} 21^{\mathrm{CIP1}}$, a protein involved in cell cycle arrest, and Bax, a mitochondrial pro-apototic protein (35). p53 contains a total of 20 lysine residues. It is not at present clear how many of these 


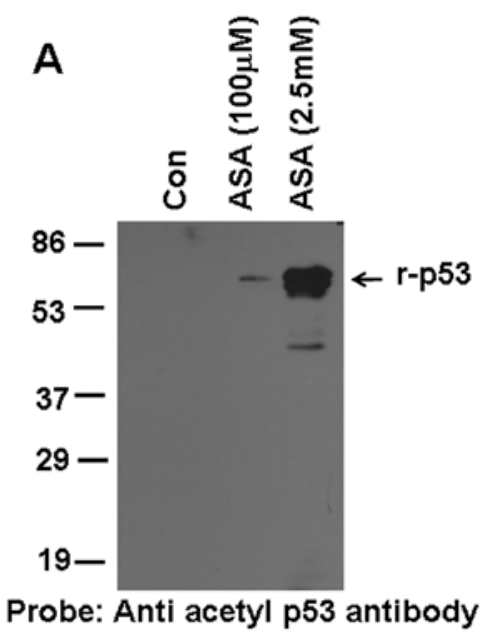

B

\section{Probe: Anti p53 antibody}

Figure 1. Aspirin induces the acetylation of p53 in vitro. (A) Bacterially expressed recombinant p53 (r-p53) (5 ng) was incubated in the absence (control) or presence of aspirin at $100 \mu \mathrm{M}$ or $2.5 \mathrm{mM}$ as indicated for $24 \mathrm{~h}$ at room temperature. The samples were immunoblotted by probing with antiacetyl p53 antibody (Cell Signaling Inc.) specific for the recognition of acetylation at Lys 382. Protein bands were detected using enhanced chemiluminescence. (B) The blot in A was stripped and reprobed with anti-p53 antibody (loading control).

lysine residues, besides K382, are acetylated by aspirin (35). In view of previous reports on the ability of aspirin to acetylate proteins through a transacetylation reaction $(8,12-15)$, it is likely that aspirin targets multiple lysine residues on p53. Consistent with this notion, we observed that the incubation of purified recombinant p53 with low $(100 \mu \mathrm{M})$ as well as high ( $2.5 \mathrm{mM})$ concentrations of aspirin resulted in p53 acetylation at lysine 382 (Fig. 1A), confirming the occurrence of a non-enzymatic transacetylation reaction. It is possible that p53 acetylation by aspirin may have significant consequences on the ability of p53 to modulate its target gene expression. The battery of p53-regulated genes comprises more than 150 genes, including those which induce growth arrest, stimulate DNA repair, and regulate apoptosis and anti-angiogenic proteins (36). The ability of aspirin to acetylate p53 in cell cultures as well as in vitro is a very important observation in view of its chemopreventive properties. It remains to be determined whether or not the anticancer properties of aspirin occur as a result of the acetylation of p53 and the subsequent activation of its target genes.

\section{Aspirin acetylates multiple cellular proteins}

The ability of aspirin to acetylate p53 (35) suggests that under similar conditions aspirin may target other acetylable cellular proteins. Here, we present a new approach for the detection of proteins acetylated by aspirin in cells. We carried out immunoblotting experiments to detect proteins acetylated by aspirin using an anti-acetyl lysine antibody specific for the recognition of acetylated lysine residues. Since the liver is one of the first tissues to come into contact with intact aspirin following oral

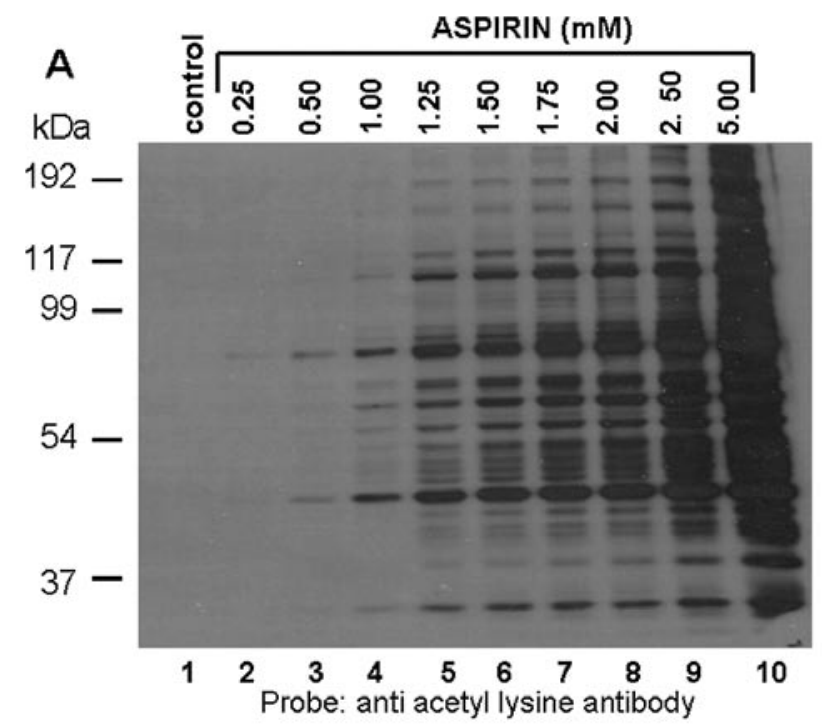

B

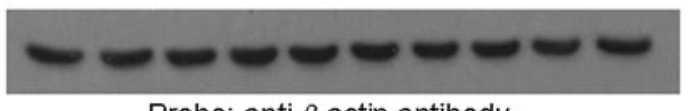

Probe: anti $\beta$-actin antibody

Figure 2. Aspirin acetylates multiple cellular proteins. (A) Concentrationdependent protein acetylation by aspirin in WB cells. WB liver epithelial cells were grown as previously described (38). Cells were left untreated or treated for $8 \mathrm{~h}$ with different concentrations of aspirin as indicated. Proteins were run on an $8 \%$ SDS-PAGE and immunoblotted with anti-acetyl lysine antibody (Cell Signaling Inc.). Protein bands were detected using enhanced chemiluminescence. (B) The blot in A was stripped and reprobed with antiß-actin antibody (loading control). Similar results were obtained in multiple cell lines.

ingestion (10,11,37), a rat liver normal epithelial cell line (38) was used. Cells were treated with different concentrations (0.25-5 mM) of aspirin for $8 \mathrm{~h}$, and lysates were prepared and immunoblotted with anti-acetyl lysine antibody. We chose to use these concentrations of aspirin in view of the use of similar concentrations by previous investigators, ranging from $0.2 \mathrm{mM}$ to $5 \mathrm{mM}$ or much higher (10,24,39-42). Fig. $2 \mathrm{~A}$ shows that aspirin induced the acetylation of few proteins at $0.25 \mathrm{mM}$ (lane 2); however, increasing amounts of acetylated proteins were detected at higher concentrations (lanes 5-10). As a loading control, the blot shown in Fig. 2A was stripped and reprobed with anti- $\beta$-actin antibody. Fig. $2 \mathrm{~B}$ shows that all lanes contained similar amounts of $\beta$-actin. These results clearly demonstrate that aspirin acetylates multiple proteins in a dose-dependent fashion. Although the profile and intensity of acetylated proteins as detected by the anti-acetyl lysine antibody at concentrations such as $250 \mu \mathrm{M}$ are lower compared to higher concentrations, we observed the acetylation of specific proteins at lower aspirin concentrations $(100 \mu \mathrm{M})$ in immunoblots probed with protein (p53)-specific anti-acetyl lysine antibodies (35). This suggests the increased sensitivity of this immunoblotting technique with protein-specific antiacetyl lysine antibodies. Acetylation of multiple proteins was also observed in colon (HT-29), lung (A549), breast (MDAMB-231), skin (SK-MEL-5) and liver (HepG2) cancer cell lines, as well as in primary cultures of normal human hepatocytes (unpublished data). Treatment of cells with salicylic acid alone failed to induce protein acetylation, suggesting that the acetyl group of aspirin is required for the observed effects. 


\section{Summary}

Aspirin is a systemic agent that has both beneficial and adverse effects throughout the body. Its beneficial effects include its analgesic, anti-inflammatory, anti-thrombotic/cardioprotective and potential chemopreventive properties. However, despite these beneficial effects, it can cause fatal gastrointestinal bleeding, hemorrhagic strokes, nephrotoxicity, and adverse effects on the central nervous system (tinnitus). The plasma of aspirin-treated patients has been shown to contain antibodies against acetylated albumin. This is sometimes associated with a number of untoward immunological reactions. Moreover, aspirin-intolerant patients are characterized by asthma, rhinitis and nasal polyps (13), suggesting that the adverse effects of aspirin include imbalances in immunological reactions. Aspirin is used as a therapeutic agent at various concentrations; therefore, it is likely that the long-term effect of even lower doses of repeatedly administered aspirin may lead to the acetylation of proteins having a longer half life. The molecular mechanisms by which aspirin exerts its chemopreventive properties, as well as some of its adverse effects, are not clearly understood. The ability of aspirin to acetylate multiple proteins as demonstrated in Fig. 2, in combination with previous reports, suggests that the acetylation of proteins may be a major factor involved in some of the unexplained effects of aspirin. The identification of these novel targets and their functions may provide improved insight into the hitherto unknown actions of this drug.

\section{Acknowledgements}

We thank Dr Shelton Earp of the University of North Carolina for granting us permission to use the WB rat liver epithelial cell line in our study. Financial support from the Department of Pharmaceutical Sciences and Cancer Biology Center is also gratefully acknowledged.

\section{References}

1. Vane JR and Botting RM: The mechanism of action of aspirin. Thromb Res 110: 255-258, 2003.

2. Chan AT, Giovannucci EL, Meyerhardt JA, Schernhammer ES, Curhan GC and Fuchs CS: Long-term use of aspirin and nonsteroidal anti-inflammatory drugs and risk of colorectal cancer. JAMA 294: 914-923, 2005.

3. Leshno M, Moshkowitz M and Arber N: Aspirin is clinically effective in chemoprevention of colorectal neoplasia: point. Cancer Epidemiol Biomarkers Prev 17: 1558-1561, 2008.

4. Yin MJ, Yamamoto Y and Gaynor RB: The anti-inflammatory agents aspirin and salicylate inhibit the activity of I(kappa)B kinase-beta. Nature 396: 77-80, 1998.

5. Grilli M, Pizzi M, Memo M and Spano P: Neuroprotection by aspirin and sodium salicylate through blockade of NF-kappa B activation. Science 274: 1383-1385, 1996.

6. McCarty MF and Block KI: Preadministration of high dose salicylates. Supressors of NF- $\kappa B$ activation may increase the chemosensitivity of many cancers: An example of proapoptotic signal modulation therapy. Integr Cancer Ther 5: 252-268, 2006.

7. Roth GJ, Machuga ET and Ozols J: Isolation and covalent structure of the aspirin-modified, active-site region of prostaglandin synthetase. Biochemistry 22: 4672-4675, 1983.

8. Pinckard RN, Hawkins D and Farr RS: In vitro acetylation of plasma proteins, enzymes and DNA by aspirin. Nature 219: 68-69, 1968.

9. Mandel HG, Cambosos NM and Smith PK: The presence of aspirin in human plasma after oral administration. J Pharmacol Exp Ther 112: 495-500, 1954
10. Bridges KR, Schmidt GJ, Jensen M, Cerami A and Bunn HF: The acetylation of hemoglobin by aspirin. In vitro and in vivo. J Clin Invest 56: 201-207, 1974.

11. Leonards JR: Presence of acetylsalicylic acid in plasma following oral ingestion of aspirin. Proc Soc Exp Biol Med 110: 304-308, 1962.

12. Rainsford KD, Shweitzer A and Brune K: Distribution of the acetyl compared with the salicyl moiety of acetylsalicylic acid. Acetylation of macromolecules in organs wherein side-effects are manifest. Biochem Pharmacol 32: 1301-1308, 1983.

13. Hawkins D, Pinckard RN and Farr RS: Acetylation of human serum albumin by acetylsalicylic acid. Science 160: 780, 1968.

14. Hoffman DR and Campbell DH: Model systems for the study of drug hypersensitivity. II. Studies on the acetylation mechanism for aspirin intolerance. J Immunol 104: 582-584, 1970.

15. Caterson RJ, Duggin GG, Horvath J, Mohandas J and Tiller D: Aspirin protein transacetylation and inhibition of prostaglandin synthetase in the kidney. Br J Pharmacol 64: 353-358, 1978.

16. Roth GJ and Majerus PW: The mechanism of the effect of aspirin on human platelets. J Clin Invest 56: 624-632, 1975.

17. Vane JR, Bakhle YS and Botting RM: Cyclooxygenases 1 and 2. Annu Rev Pharmacol Toxicol 38: 97-120, 1998.

18. Hawkins D, Pinckard RN, Crawford IP and Farr RS: Structural changes in human serum albumin induced by ingestion of acetylsalicylic acid. J Clin Invest 48: 536-542, 1969.

19. Honma K, Nakamura M and Ishikawa Y: Acetylsalicylate-human serum albumin interaction as studied by NMR spectroscopy antigenicity-producing mechanism of acetylsalicylic acid. Mol Immunol 28: 107-113, 1991.

20. Minden P and Farr RS: Human antibodies against acetylsalicylic acid-altered human serum albumin. Arthritis Rheum 10: 299, 1967.

21. Rendell M, Nierenberg J, Brannan C, Valentine JL, Stephen PM, Dodds S, Mercer P, Smith PK and Walder J: Inhibition of glycation of albumin and hemoglobin by acetylation in vitro and in vivo. $\mathrm{J}$ Lab Clin Med 108: 286-293, 1986.

22. Bjornsson TD, Schneider DE and Berger H Jr: Aspirin acetylates fibrinogen and enhances fibrinolysis. Fibrinolytic effect is independent of changes in plasminogen activator levels. J Pharmacol Exp Ther 250: 154-161, 1988.

23. Walder JA, Zaugg RH, Iwaoka RS, Watkin WG and Klotz IM: Alternative aspirins as antisickling agents: Acetyl-3,5dibromosalicylic acid. Proc Nat Acad Sci USA 74: 5499-5503, 1977.

24. Klotz IM and Tam JWO: Acetylation of sickle cell hemoglobin by aspirin. Proc Natl Acad Sci USA 70: 1313-1315, 1973.

25. Shamsuddin M, Mason RG, Ritchey JY, Honig GR and Klotz IM: Sites of acetylation of sickle cell hemoglobin by aspirin. Proc Natl Acad Sci USA 71: 4693-4697, 1974.

26. Xu ASL, Ohba Y, Vida L, Labotka RJ and London RE: Aspirin acetylation of BLys-82 of human hemoglobin: NMR study of acetylated hemoglobin tsurumai. Biochem Pharmacol 60: 917-922, 2000.

27. DeFuria FG, Cerami A, Bunn HF, Lee YS and Peterson CM: The effect of aspirin on sickling and oxygen affinity of erythrocytes. Proc Natl Acad Sci USA 70: 3707-3710, 1973.

28. Greenberg J, Ohene-Frempong K, Halus J, Way C and Schwartz E: Trial of low doses of aspirin as prophylaxis in sickle cell disease. J Pediatr 102: 781-784, 1983.

29. Watala $\mathrm{C}$ and Gwozdzinski K: Effect of aspirin on conformation and dynamics of membrane proteins in platelets and erythrocytes. Biochem Pharmacol 45: 1343-1349, 1993.

30. Green FA and Jung CY: Acetylation of erythrocytic membrane peptides by aspirin. Transfusion 21: 55-58, 1981.

31. Macdonald JM, LeBlanc DA, Haas AL and London RE: An NMR analysis of the reaction of ubiquitin with [acetyl-1-13C] aspirin. Biochem Pharmacol 57: 1233-1244, 1999.

32. Cherian M and Abraham EC: Glycation of human lens crystallins: Effect of age and aspirin treatment. Opthal Res 25: 349-354, 1993.

33. Qin W, Smith JB and Smith DL: Reaction of aspirin with cysteinyl residues of lens gamma-crystallins: a mechanism for the proposed anti-cataract effect of aspirin. Biochem Biophys Acta 1181: 103-110, 1993.

34. Hun-Opfer C and Mata-Segreda JF: Non-enzymatic acetylation of proteins by aspirin as protection against secondary complications of diabetes mellitus. Acta Physiol Pharmacol Latinoam 36: 313-316, 1986.

35. Alfonso LF, Srivenugopal KS, Arumugam TV, Abbruscato TJ, Weidanz JA and Bhat GJ: Aspirin inhibits camptothecin-induced p2 $1^{\mathrm{CIP1}}$ levels and potentiates apoptosis in human breast cancer cells. Int J Oncol 34: 597-608, 2009. 
36. Bode AM and Dong Z: Post-translational modification of p53 in tumorigenesis. Nature 4: 793-805, 2004.

37. Morikawa M, Inoue M, Tsuboi M and Sugiura M: Studies on aspirin esterase of human serum. Jpn J Pharmacol 29: 581-586, 1979.

38. Krishna SB, Alfonso LF, Thekkumkara TJ, Abbruscato TJ and Bhat GJ: Angiotensin II induces phosphorylation of glucose regulated protein-75 in WB rat liver cells. Arch Biochem Biophys 457, 16-28, 2007.

39. Dikshit P, Chatterjee M, Goswami A, Mishra A and Jana NR: Aspirin induces apoptosis through the inhibition of proteosome function. J Biol Chem 281: 29228-29235, 2006.
40. Qiao L, Hanif R, Sphicas E, Shiff SJ and Rigas B: Effect of aspirin on induction of apoptosis in HT-29 human colon adenocarcinoma cells. Biochem Pharmacol 55: 53-64, 1998.

41. Luciani MG, Campregher C and Gasche C: Aspirin blocks proliferation in colon cells by inducing G1 arrest and apoptosis through activation of the checkpoint kinase ATM. Carcinogenesis 28: 2207-2217, 2007.

42. Sonnemann J, Huls I, Siler M, Palani CM, Hong LTT, Volker U, Kroemer HK and Beck JF: Histone deacetylase inhibitors and aspirin interact synergistically to induce cell death in ovarian cancer cells. Oncol Rep 20: 219-224, 2008 